\title{
Effects of acute administration of selective serotonin reuptake inhibitors on sympathetic nerve activity
}

\author{
R.V. Tiradentes ${ }^{1,2}$, J.G.P. Pires ${ }^{2,3}$, N.F. Silva ${ }^{4}$, A.G. Ramage ${ }^{5}$, C.H. Santuzzi ${ }^{1,2}$ and \\ H.A. Futuro Neto $3,4,6$ \\ ${ }^{1}$ Departamento de Ciências Fisiológicas, Centro de Ciências da Saúde, Universidade Federal do Espírito Santo, \\ Vitória, ES, Brasil \\ ${ }^{2}$ Centro Universitário do Espírito Santo, Colatina, ES, Brasil \\ ${ }^{3}$ Escola de Medicina da Empresa Brasileira de Ensino, Vitória, ES, Brasil \\ ${ }^{4}$ Departamento de Morfologia, Centro de Ciências da Saúde, Universidade Federal do Espírito Santo, Vitória, ES, Brasil \\ ${ }^{5}$ Department of Neuroscience, Physiology and Pharmacology, University College London, London, UK \\ ${ }^{6}$ Escola Superior de Ciências da Saúde, Santa Casa de Misericórdia de Vitória, Vitória, ES, Brasil
}

\begin{abstract}
Serotonergic mechanisms have an important function in the central control of circulation. Here, the acute effects of three selective serotonin (5-HT) reuptake inhibitors (SSRIs) on autonomic and cardiorespiratory variables were measured in rats. Although SSRIs require 2-3 weeks to achieve their full antidepressant effects, it has been shown that they cause an immediate inhibition of 5-HT reuptake. Seventy male Wistar rats were anesthetized with urethane and instrumented to record blood pressure, heart rate, renal sympathetic nerve activity (RSNA), and respiratory frequency. At lower doses, the acute cardiovascular effects of fluoxetine, paroxetine and sertraline administered intravenously were insignificant and variable. At middle and higher doses, a general pattern was observed, with significant reductions in sympathetic nerve activity. At $10 \mathrm{~min}$, fluoxetine ( 3 and $10 \mathrm{mg} / \mathrm{kg}$ ) reduced RSNA by $-33 \pm 4.7$ and $-31 \pm 5.4 \%$, respectively, without changes in blood pressure; 3 and $10 \mathrm{mg} / \mathrm{kg}$ paroxetine reduced RSNA by $-35 \pm 5.4$ and $-31 \pm 5.5 \%$, respectively, with an increase in blood pressure $+26.3 \pm 2.5 ; 3 \mathrm{mg} / \mathrm{kg}$ sertraline reduced RSNA by $-59.4 \pm 8.6 \%$, without changes in blood pressure. Sympathoinhibition began $5 \mathrm{~min}$ after injection and lasted approximately $30 \mathrm{~min}$. For fluoxetine and sertraline, but not paroxetine, there was a reduction in heart rate that was nearly parallel to the sympathoinhibition. The effect of these drugs on the other variables was insignificant. In conclusion, acute peripheral administration of SSRIs caused early autonomic cardiovascular effects, particularly sympathoinhibition, as measured by RSNA. Although a peripheral action cannot be ruled out, such effects are presumably mostly central.
\end{abstract}

Key words: Fluoxetine; Paroxetine; Renal nerve activity; Serotonin; Sertraline; Sympathetic activity

\section{Introduction}

A large body of evidence has established the importance of the central neurotransmitter serotonin $(5-\mathrm{HT})$ in the control of the autonomic nervous system, among other functions (1). Several classes of therapeutically useful drugs act as either agonists or antagonists upon one or more of the 5-HT receptor subtypes (1). Another important group of serotonergic drugs, the selective serotonin reuptake inhibitors (SSRIs), act primarily by inhibition of the 5-HT transporter (SERT) located on the presynaptic membrane. These drugs are widely used to treat psychiatric disorders, particularly monopolar depression. It is well established that they do not exert their full effect until 2-3 weeks after the start of treatment (2). These agents are also occasionally used to treat neurocardiogenic syncope, despite lack of consistent evidence regarding their efficacy (3).

In anesthetized rats, activation of several central 5-HT receptor subtypes, including $5-\mathrm{HT}_{1 \mathrm{~A}}$ and $5-\mathrm{HT}_{2 \mathrm{~A}}$, causes sympathoinhibition (1). However, the overall picture is not entirely clear. Peripheral administration of several 5-HT receptor antagonists, particularly $5-\mathrm{HT}_{2}$ blockers, is associated with hypotension and/or sympathoinhibition (1). It should also be noted that some raphe nuclei, which are mainly serotonergic, play a role in the central control of respiration in mammals $(4,5)$. However, little is known

Correspondence: H.A. Futuro Neto, Departamento de Morfologia, CCS, UFES, Av. Marechal Campos, 1468, 29042-751 Vitória, ES, Brasil. E-mail: futuront@gmail.com 
about the short-term respiratory effects of intravenously injected serotonergic drugs, especially the SSRIs.

Therefore, to better characterize their acute cardiovascular, respiratory and sympathetic effects, we tested three distinct SSRIs administered intravenously in anesthetized rats. The drug doses chosen were those commonly employed in the literature (6-9). Pharmacokinetic and pharmacodynamic properties were taken into account. For instance, at lower doses sertraline has greater potency for SERT inhibition. Generally speaking, the first dose of all tested SSRIs was comparable to the dose range used in the clinical setting. Owing to the high selectivity of the SSRIs for SERT, which is at least 300 times greater $(2,10)$ than their inhibitory effect on the norepinephrine transporter, we can be sure that the observed effects are a result of serotonergic mechanisms.

\section{Material and Methods}

\section{Animal care and experimental groups}

Male Wistar rats weighing 250-300 g from our breeding colony were used (Centro de Ciências da Saúde, Universidade Federal do Espírito Santo). The animals $(n=70)$ were randomized to 10 experimental groups as follows: vehicle; 1,3 , and $10 \mathrm{mg} / \mathrm{kg}$ fluoxetine; 1,3 , and $10 \mathrm{mg} / \mathrm{kg}$ paroxetine; and $0.3,1$, and $3 \mathrm{mg} / \mathrm{kg}$ sertraline. The animals were kept on a 12-h light/dark cycle under artificial lighting and at a controlled temperature of $22^{\circ} \mathrm{C}$ with access to food and water ad libitum.

All procedures were conducted in accordance with the Biomedical Research Guidelines for the Care and Use of Laboratory Animals, as stated by Federação das Sociedades Brasileiras de Biologia Experimental (FeSBE). The experimental protocol was approved by the Animal Use Committee at Escola Superior de Ciências, Santa Casa de Misericórdia (No. 021/2007, CEUA/ EMESCAM, Vitória, ES, Brazil).

\section{Surgical procedures and experimental design}

Rats were initially anesthetized with $3 \%$ halothane in an induction chamber. Anesthesia was maintained with $1.2 \mathrm{~g} / \mathrm{kg}$ urethane (iv) and supplementary doses of urethane, as required. A tracheotomy was performed in all animals, and respiratory frequency (RF) was continuously monitored, using a pneumotachograph (model 0000, A. Fleish, Switzerland) and a low-pressure transducer (DP45, Valadine Engeneering Corp., USA) connected to a polygraph (RS 3400, Gould Electronics, USA). The femoral artery was cannulated to measure blood pressure using a pressure transducer (P23XL, Viggo-Spectramed, USA), and the heart rate (HR) was calculated electronically from the blood pressure measurements using a rate meter (Biotach, 13-64616-66, Gould Electronics). The left femoral vein was cannulated for drug administration. Rectal temperature was maintained between $37^{\circ}$ and $37.5^{\circ} \mathrm{C}$ with a thermostatically controlled heating blanket (Harvard, USA).
The left kidney was exposed via a retroperitoneal approach, and a renal nerve bundle was dissected carefully and freed from the surrounding tissue under microscope magnification $(32 \times)$. The nerve was placed on a bipolar electrode made of silver and covered with mineral oil. The nerve activity was displayed on an oscilloscope (TDS 210, Tektronix, USA) and monitored by means of an audio amplifier (Neurolog NL120, Digitimer Ltd., UK). The signal was amplified (5 to 10 k; Neurolog NL104, Digitimer Ltd.) and filtered (low frequency: $10 \mathrm{~Hz}$, high frequency: $1 \mathrm{kHz}$, with a $60-\mathrm{Hz}$ notch; Neurolog NL126, Digitimer Ltd.). The renal nerve activity was reported as the difference $(\Delta)$ from each basal value. All cardiovascular, respiratory and nerve activity data were digitized (MP 100, BIOPAC Systems, USA) and stored on a PC hard disk for processing.

Before starting the experimental protocol, the baroreflex function was assessed in each animal using an iv injection of $50 \mu \mathrm{g} / \mathrm{kg}$ phenylephrine. All animals included in the study displayed a typical bradycardia reflex. The protocol included an iv injection of saline (as control) or the drug and monitoring of renal sympathetic nerve activity (RSNA), mean arterial pressure, $\mathrm{HR}$, and RF for 30 min at 5 min intervals.

\section{Drugs}

The following substances were used in this study: halothane (Cristália, Brazil), urethane (Sigma, USA), phenylephrine (Sigma), fluoxetine (PharmaSpecial, USA), paroxetine (PharmaSpecial) and sertraline (Tocris, USA). The drugs were freshly prepared and injected iv using $0.9 \%$ saline as a vehicle.

\section{Statistical analysis}

Data are reported as means \pm SE for 7 animals per group. Comparisons of the mean differences $(\Delta)$ of the parameters were analyzed using two-way repeated measures ANOVA followed by the Tukey multiple comparison test. Differences were considered to be statistically significant at $\mathrm{P}<0.05$.

\section{Results}

In general, the acute cardiovascular effects of the three SSRIs were quite mild and variable at lower doses. At the middle and higher doses, a general pattern toward a significant dose-dependent reduction in sympathetic nerve activity was observed, as measured from the renal nerve. The results are reported as a range from the least selective (fluoxetine) to the most selective (sertraline) SSRI. Baseline parameters for the experimental groups are reported in Table 1.

\section{Effects of fluoxetine}

Fluoxetine at $1 \mathrm{mg} / \mathrm{kg}$ did not cause any obvious changes in the measured parameters (Figure 1). However, 
Table 1. Baseline values for heart rate $(\mathrm{HR})$ and mean arterial pressure (MAP) of anesthetized Wistar rats in each experimental group ( $\mathrm{n}=7$ per group)

\begin{tabular}{lcc}
\hline Groups & HR $(\mathrm{bpm})$ & MAP $(\mathrm{mmHg})$ \\
\hline $\begin{array}{l}\text { Vehicle } \\
\text { Fluoxetine }\end{array}$ & $421 \pm 20$ & $89 \pm 3.0$ \\
$1 \mathrm{mg} / \mathrm{kg}$ & $376 \pm 15$ & $84 \pm 7.8$ \\
$3 \mathrm{mg} / \mathrm{kg}$ & $384 \pm 20$ & $86 \pm 4.3$ \\
$\quad 10 \mathrm{mg} / \mathrm{kg}$ & $360 \pm 14$ & $91 \pm 5.3$ \\
Paroxetine & & \\
$1 \mathrm{mg} / \mathrm{kg}$ & $394 \pm 12$ & $90 \pm 2.7$ \\
$3 \mathrm{mg} / \mathrm{kg}$ & $382 \pm 14$ & $90 \pm 4.6$ \\
$10 \mathrm{mg} / \mathrm{kg}$ & $375 \pm 21$ & $88 \pm 4.4$ \\
Sertraline & & \\
$0.3 \mathrm{mg} / \mathrm{kg}$ & $360 \pm 9$ & $93 \pm 3.5$ \\
$1 \mathrm{mg} / \mathrm{kg}$ & $386 \pm 19$ & $94 \pm 4.7$ \\
$3 \mathrm{mg} / \mathrm{kg}$ & $393 \pm 28$ & $97 \pm 9.1$ \\
\hline
\end{tabular}

at doses of 3 and $10 \mathrm{mg} / \mathrm{kg}$, similar and significant reductions in renal nerve activity were observed, with minor changes in HR, blood pressure, and RF. The change in RSNA at $10 \mathrm{~min}$ after 3 or $10 \mathrm{mg} / \mathrm{kg}$ fluoxetine was $-33 \pm$ 4.7 or $-31 \pm 5.4 \%$, respectively, compared to $-8.5 \pm 9 \%$ in the control group $(\mathrm{P}<0.05)$. The reduction in RSNA caused by 3 and $10 \mathrm{mg} / \mathrm{kg}$ fluoxetine was detected $5 \mathrm{~min}$ after the intravenous injection (along with a transient bradycardia), and achieved its maximal reduction at $15 \mathrm{~min}$, remaining stable during the rest of the experimental period.

\section{Effects of paroxetine}

At the lower dose $(1 \mathrm{mg} / \mathrm{kg})$, intravenous paroxetine did not change the measured parameters significantly, except for sympathetic nerve activity, which displayed a small but significant $(P<0.05)$ reduction compared with control values at some experimental times (Figure 2). A consistent, statistically significant decrease in renal nerve activity was observed with the 3 and $10 \mathrm{mg} / \mathrm{kg}$ doses However, no apparent dose-dependency was observed.

Sympathoinhibition reached a maximum 5 min after the iv injection and was stable thereafter. The changes in nerve activity at $10 \mathrm{~min}$ after 3 or $10 \mathrm{mg} / \mathrm{kg}$ paroxetine were $-35 \pm 5.4$ and $-31 \pm 5.5 \%$, respectively, compared to $-8.5 \pm 9 \%$ in the control group $(P<0.05)$. Such renal sympathoinhibition was not accompanied by a reduction in $\mathrm{HR}$; however, a significant increase in blood pressure, which reached a maximum at $10 \mathrm{~min}$, was observed $(+26.3 \pm 2.5$ vs $-2.0 \pm 2.5 \mathrm{mmHg}$ in the control group; $\mathrm{P}<0.05)$

Additionally, a late increase in HR (statistically significant from 20 to $30 \mathrm{~min}$ ) accompanied by hypertension was observed with a $10 \mathrm{mg} / \mathrm{kg}$ dose of paroxetine $(+37 \pm 9$ vs $+10 \pm 8.4 \mathrm{bpm}$ in the control group at $20 \mathrm{~min} ; \mathrm{P}<0.05)$. The higher dose of paroxetine also caused a mild but significant respiratory stimulation $(+15 \pm 3.7$ vs $+0.9 \pm 2.4 \mathrm{cpm}$; at 20 min, $\mathrm{P}<0.05$ ).

\section{Effects of sertraline}

No consistent response pattern was observed (Figure 3) at the lower dose of sertraline $(0.3 \mathrm{mg} / \mathrm{kg})$. Sertraline at 1 and $3 \mathrm{mg} / \mathrm{kg}$ caused a dose-related and significant decrease in sympathetic nerve activity. For example, the change in RSNA at $15 \mathrm{~min}$ after 1 or $3 \mathrm{mg} / \mathrm{kg}$ sertraline was $-26.4 \pm 10.1$ and $-59.4 \pm 8.6 \%$, respectively, compared with $-8.0 \pm 7.6 \%$ in the control group $(\mathrm{P}<0.05)$
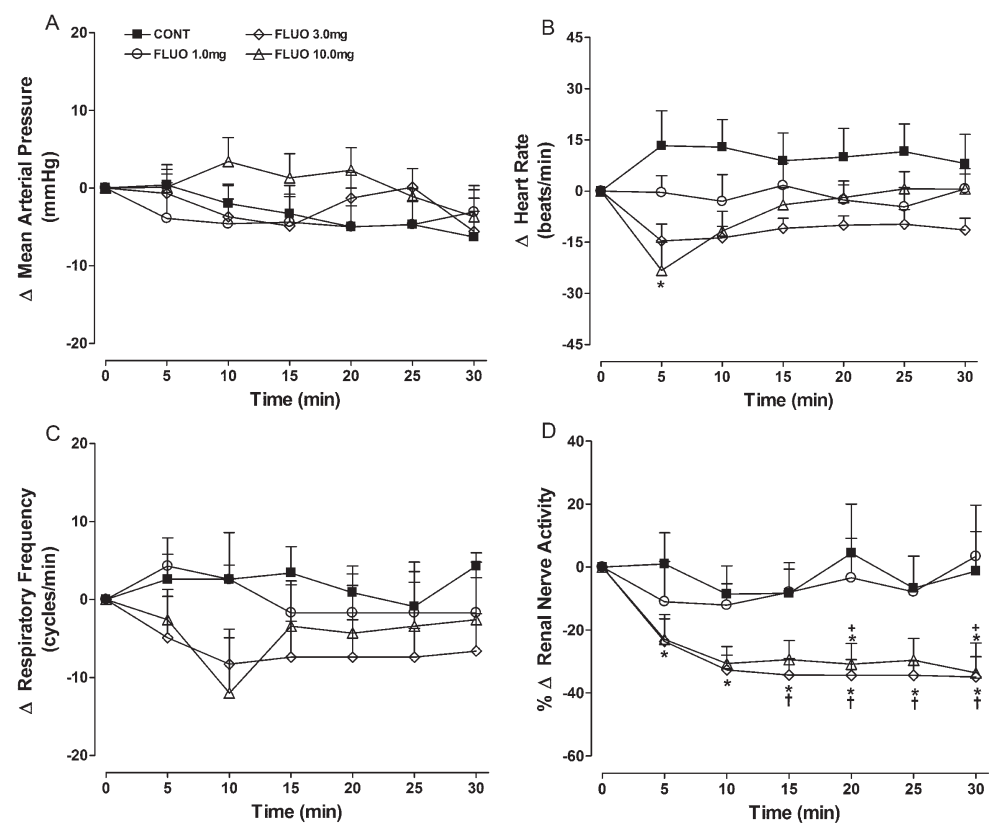

Figure 1. Effects of iv fluoxetine $(1,3$, and $10 \mathrm{mg} / \mathrm{kg}$ ) administration on mean changes $(\Delta)$ in $A$, mean arterial pressure; $B$, heart rate; $C$, respiratory frequency; $D$, renal nerve activity. Data are reported as means \pm SE for $n=7$ rats per group. CONT: control; FLUO: fluoxetine (1, 3 , or $10 \mathrm{mg} / \mathrm{kg}$ ). ${ }^{*} \mathrm{P}<0.05$, FLUO (1, 3, and $10 \mathrm{mg} /$ $\mathrm{kg}$ ) vs CONT; ${ }^{\dagger} \mathrm{P}<0.05,3 \mathrm{mg} / \mathrm{kg}$ FLUO vs $1 \mathrm{mg} /$ $\mathrm{kg} \mathrm{FLUO;}{ }^{+} \mathrm{P}<0.05,10 \mathrm{mg} / \mathrm{kg}$ FLUO vs $1 \mathrm{mg} / \mathrm{kg}$ FLUO (ANOVA followed by the Tukey test). 

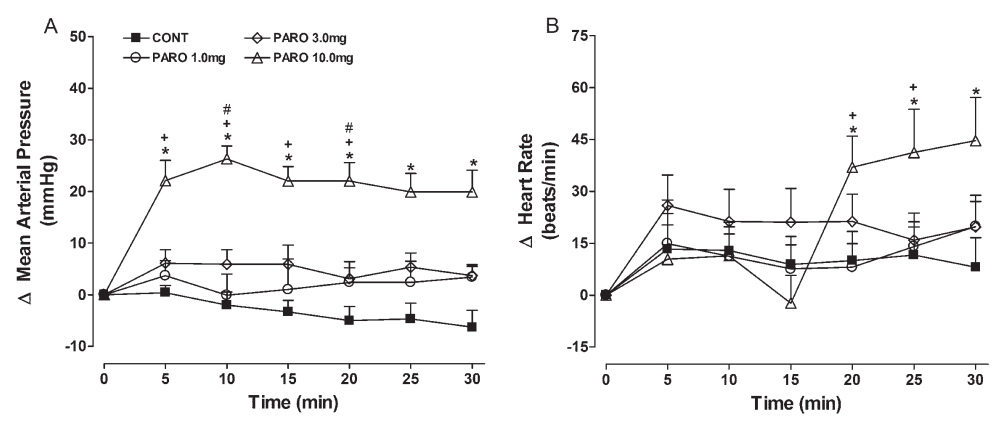

Figure 2. Effects of iv paroxetine $(1,3$, and $10 \mathrm{mg} / \mathrm{kg}$ ) administration on mean changes $(\Delta)$ in $A$, mean arterial pressure; $B$, heart rate; $C$, respiratory frequency; $D$, renal nerve activity. Data are reported as means \pm SE for $n=7$ rats per group. CONT: control; PARO: paroxetine (1, 3 , or $10 \mathrm{mg} / \mathrm{kg})$. ${ }^{*} \mathrm{P}<0.05$, PARO $(1,3$, and $10 \mathrm{mg} / \mathrm{kg}$ ) vs CONT; ${ }^{+} \mathrm{P}<0.05$, PARO $10 \mathrm{mg} / \mathrm{kg}$ vs PARO $1 \mathrm{mg} / \mathrm{kg}$; ${ }^{*} \mathrm{P}<0.01$, PARO $10 \mathrm{mg} / \mathrm{kg}$ vs PARO $3 \mathrm{mg} / \mathrm{kg}$ (ANOVA followed by the Tukey test).
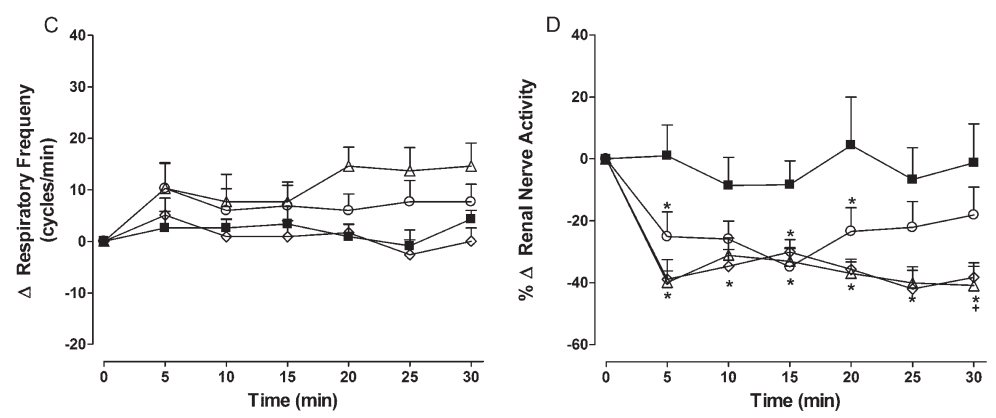

A reduction in renal nerve activity was detected as early as $5 \mathrm{~min}$ after the iv injection, and gradually intensified during the experimental period. A late increase in blood pressure was observed with $3 \mathrm{mg} / \mathrm{kg}$ sertraline $(+12 \pm 3.5 \mathrm{vs}-4.7 \pm 3.1 \mathrm{mmHg}$ in the controls at $25 \mathrm{~min}$, $\mathrm{P}<0.05)$.

The drug effect on EF was small and inconsistent regardless of the dose used.

\section{Discussion}

The main finding of this research was that the peripheral administration of SSRIs caused acute autonomic cardiovascular and respiratory effects in the anesthetized rat. Because three distinct compounds with similar selectivity regarding the SERT system were used, it can be inferred that these are class effects. The most
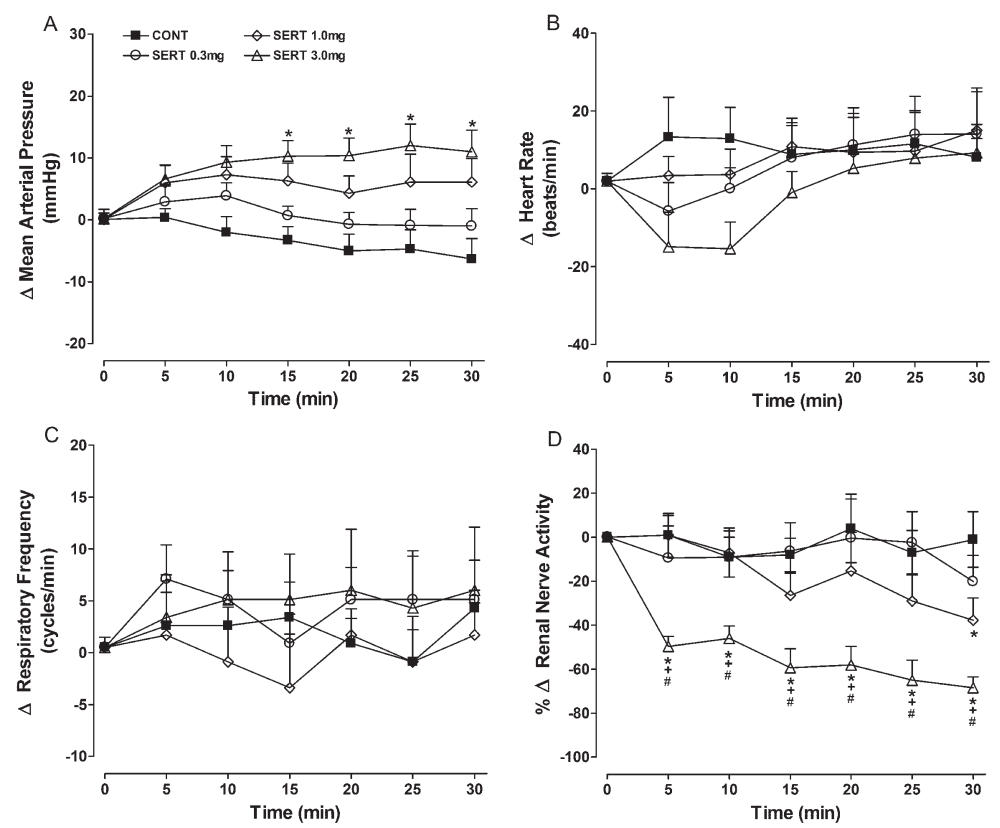

Figure 3. Effects of iv sertraline $(0.3,1$, and $3 \mathrm{mg} / \mathrm{kg}$ ) administration on mean changes $(\Delta)$ in $A$, mean arterial pressure; $B$, heart rate; $C$, respiratory frequency; $D$, renal nerve activity. Data are reported as means \pm SE for $n=7$ rats per group. CONT: control; SERT: sertraline (0.3, 1 , or $3 \mathrm{mg} / \mathrm{kg})$. ${ }^{*} \mathrm{P}<0.05$, SERT $(0.3,1$, and $3 \mathrm{mg} / \mathrm{kg}$ ) vs CONT; ${ }^{+} \mathrm{P}<0.01,3 \mathrm{mg} / \mathrm{kg}$ SERT vs $0.3 \mathrm{mg} / \mathrm{kg}$ SERT; ${ }^{\#} \mathrm{P}<0.01,3 \mathrm{mg} / \mathrm{kg}$ SERT $v s$ $1 \mathrm{mg} / \mathrm{kg}$ SERT (ANOVA followed by the Tukey test). 
consistent effect of SSRIs in this study was an early and generally sustained sympathoinhibition, as measured by renal sympathetic nerve activity.

Fluoxetine ( 3 and $10 \mathrm{mg} / \mathrm{kg}$ ) provoked a significant reduction in renal sympathetic activity from 5 min after injection up to $30 \mathrm{~min}$, without any significant change in blood pressure; similarly, $3 \mathrm{mg} / \mathrm{kg}$ sertraline produced a significant reduction in renal sympathetic activity from 5 min after injection up to $30 \mathrm{~min}$, accompanied by a significant increase in arterial blood pressure, but only from $15 \mathrm{~min}$. On the other hand, 1,3 , and $10 \mathrm{mg} / \mathrm{kg}$ paroxetine all induced a robust and significant reduction in RSNA. Concerning blood pressure, a significant increase was only observed at the highest dose $(10 \mathrm{mg} / \mathrm{kg})$. These results suggest that the effects of SSRIs on renal sympathetic activity and on blood pressure are at least partially dissociated. To better explain these results, we suggest that peripheral resistance is the result of the active state of various vascular beds. Our results focus on the renal vascular bed; and despite the importance of this vascular circuit, we must acknowledge that it is not the only one involved in the generation of the systemic arterial blood pressure. The dissociation of sympathetic renal nerve activity from changes in blood pressure for the various SSRIs and for the various doses, allows us to speculate that the influence of baroreceptor activity, although present, was not a key influence on the observed changes in renal sympathetic activity.

Since the SSRIs were injected intravenously, a peripheral effect cannot be entirely ignored. On the other hand, the acute participation of SSRIs through various CNS mechanisms is well established. Regarding the brain regions involved in the reduction of sympathetic activity to the kidney, we can suggest that the medullary raphe nuclei are possible candidates, since they are serotonergic and participate in the modulation of sympathetic activity through projections to the ventrolateral medulla (1).

Previous studies have shown that changes in sympathetic tonus, known as differential sympathetic activation, are variable among several target structures (11-13). Thus, we cannot be sure that the observed reduction in heart rate was solely the consequence of a reduction in

\section{References}

1. Ramage AG, Villalon CM. 5-Hydroxytryptamine and cardiovascular regulation. Trends Pharmacol Sci 2008; 29: 472481, doi: 10.1016/j.tips.2008.06.009.

2. Belmaker RH, Agam G. Major depressive disorder. N Engl J Med 2008; 358: 55-68, doi: 10.1056/NEJMra073096.

3. Medow MS, Stewart JM, Sanyal S, Mumtaz A, Sica D, Frishman WH. Pathophysiology, diagnosis, and treatment of orthostatic hypotension and vasovagal syncope. Cardiol Rev 2008; 16: 4-20, doi: 10.1097/CRD.0b013e31815c8032.

4. Alvarenga RM, Pires JG, Futuro Neto HA. Functional mapping of the cardiorespiratory effects of dorsal and the sympathetic tonus to the heart. In other words, a possible vagal component in this bradycardia, or even a peripheral direct effect on the heart, cannot be ruled out.

The observed changes in blood pressure were more variable than the other parameters measured. An interesting finding was the increase in blood pressure as a result of the higher doses of paroxetine, but not with the other drugs studied. Because blood pressure has several cardiac and vascular elements, it is difficult to determine the sole source of these changes. Nevertheless, it is clear that sympathoinhibition was an important factor in the hypotensive acute response to the SSRIs.

Although a consistent pattern did not emerge, respiration was also affected by the intravenous administration of the SSRIs. Paroxetine, particularly at the higher dose, caused an increase in RF. However, this was not observed with fluoxetine or sertraline, in which the respiratory effects were mild and did not differ from the effect of the vehicle. These results do not exclude a role for central $5-\mathrm{HT}$ in the brainstem respiration circuitry because the $5-\mathrm{HT}$ effects in this regard are complex and have excitatory as well as inhibitory effects $(4,5,14)$.

One limitation of the present study was the use of anesthetized animals, as general anesthetics could affect the influence of SSRIs on autonomic and cardiorespiratory regulation. Nevertheless, urethane has been shown to be one the best anesthetic agents with respect to the maintenance of cardiovascular reflexes (15).

Although most of the therapeutic effects of SSRIs have a delay of several weeks, these drugs display important acute effects, particularly upon cardiovascular parameters. However, whether these effects are relevant to the beneficial effects of these agents in the treatment of neurocardiogenic syncope in humans (3) remains to be determined.

\section{Acknowledgments}

The authors thank Mr. Mário A. Dantas (UFES) for technical assistance. Research supported by a CNPq research grant to R.V. Tiradentes, and a CAPES grant to C.H. Santuzzi. median raphe nuclei in the rat. Braz J Med Biol Res 2005; 38: 1719-1727, doi: 10.1590/S0100-879X2005001100022.

5. Yu SY, Wang GM, Wang H, Zhang H, Li Q. Raphe pallidus modulates Botzinger complex-induced inhibition of the phrenic nerve activity in rats. Eur J Neurosci 2011; 34: 1113-1120, doi: 10.1111/j.1460-9568.2011.07837.x.

6. Angulo J, Bischoff E, Gabancho S, Cuevas P, Saenz de Tejada I. Vardenafil reverses erectile dysfunction induced by paroxetine in rats. Int J Impot Res 2003; 15: 90-93, doi: 10.1038/sj.ijir.3900950.

7. Pires JG, Bonikovski V, Futuro-Neto HA. Acute effects of 
selective serotonin reuptake inhibitors on neurolepticinduced catalepsy in mice. Braz J Med Biol Res 2005; 38: 1867-1872, doi: 10.1590/S0100-879X2005001200015.

8. Richardson NR, Roberts DC. Fluoxetine pretreatment reduces breaking points on a progressive ratio schedule reinforced by intravenous cocaine self-administration in the rat. Life Sci 1991; 49: 833-840, doi: 10.1016/0024-3205(91)90248-A.

9. Valentino RJ, Curtis AL, Parris DG, Wehby RG. Antidepressant actions on brain noradrenergic neurons. J Pharmacol Exp Ther 1990; 253: 833-840.

10. Owens MJ, Morgan WN, Plott SJ, Nemeroff CB. Neurotransmitter receptor and transporter binding profile of antidepressants and their metabolites. J Pharmacol Exp Ther 1997; 283: 1305-1322.

11. Futuro-Neto $\mathrm{HA}$, Coote $\mathrm{JH}$. Changes in sympathetic activity to heart and blood vessels during desynchronized sleep. Brain Res 1982; 252: 259-268, doi: 10.1016/0006-8993(82)
90393-6.

12. Peterson DF, Coote JH, Gilbey MP, Futuro-Neto HA. Differential pattern of sympathetic outflow during upper airway stimulation with smoke. Am J Physiol 1983; 245: R433-R437.

13. Goldstein DS. Differential responses of components of the autonomic nervous system. Handb Clin Neurol 2013; 117: 13-22, doi: 10.1016/B978-0-444-53491-0.00002-X.

14. Hilaire $G$, Voituron $N$, Menuet $C$, Ichiyama RM, Subramanian $\mathrm{HH}$, Dutschmann M. The role of serotonin in respiratory function and dysfunction. Respir Physiol Neurobiol 2010; 174: 76-88, doi: 10.1016/j.resp.2010.08.017.

15. Shimokawa A, Kunitake T, Takasaki M, Kannan $H$. Differential effects of anesthetics on sympathetic nerve activity and arterial baroreceptor reflex in chronically instrumented rats. J Auton Nerv Syst 1998; 72: 46-54, doi: 10.1016/S0165-1838(98)00084-8. 